Please do not remove this page

RMIT

UNIVERSITY

\title{
Organisational innovation
}

McMurray, Adela; O'Neill, Peter; Buckeridge, John; Cox, Julie

https://researchrepository.rmit.edu.au/esploro/outputs/9921860732101341/filesAndLinks?institution=61RMIT_INST\&index=null

McMurray, A., O'Neill, P., Buckeridge, J., \& Cox, J. (2008). Organisational innovation. Monash Business

Review, 4(3), 46-47. https://doi.org/10.2104/mbr08057

Published Version: https://doi.org/10.2104/mbr08057

Repository homepage: https://researchrepository.rmit.edu.au

(c) 2008 Monash University ePress

Downloaded On 2023/04/26 21:57:53 +1000

Please do not remove this page 


\title{
Organisational innovation
}

\author{
Adela McMurray, Peter O’Neill, John Buckeridge and \\ Julie Wolfram-Cox identify challenges and blockages \\ to skills acquisition in the technical professions.
}

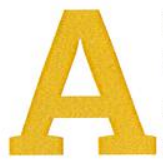

ustralia's future economy, prosperity and well being are tied to the skills and productive capacity of its workforce. This study maximises Australia's technological capability and national competitive and innovative advantage through the development of an innovative research-based skills framework for use by government, educational institutions and industry.

The study develops an emerging skills conceptual framework that provides both guiding principles and industry-specific initiatives to assist recruitment and retention in the technical professions within Australia's engineering, mining, health and manufacturing industries.

Engineering, mining and health were selected due to their rapid expansion and major contributions to the Australian economy. Manufacturing was selected as a comparative industry sector that maintains an important economic role, but suffering in terms of employment (2.1 per cent reduction over the past five years DEWR 2007), recruitment, retention and training.

The study addresses gaps in the skills formation literature in order to identify emerging jobs and assist with Australia's future economic development. It does so through a two stage comparative analysis of industry and organisational strategy, with specific attention to cultural diversity and the power of language.

Todate there is no systematic framework to anticipate changing professional and technical needs in Australia. Furthermore, there is sparse research in this area that has impacted on and influenced industry policy.
In particular, there is a need for in-depth comparative studies of the technical professions to identify key challenges (and potential blockages) for organisational innovation and industry policy. This study provides the basis for inter-industry learning necessary to facilitate Australia's continued development beyond the recent resources boom.

This study seeks to examine the use and effects of industrial skills shortages and identifies key strategic, cultural and discursive factors necessary to shift discussion from existing shortage to skills formation and growth. The term organisational innovation refers to the dedication of processes and resources to capitalise on opportunities, and growth in future skills and emerging jobs.

The scope of the study is restricted to professional skills as these skills are likely to require dedicated advanced education and infrastructure and require careful long-term planning if they are to be developed and retained within Australia. Thus, the following six questions have been used to guide the current research stream:

1.What are the emerging skills within the technical professions?

2.What are the knowledge bases required for emerging skills?

3.What role does organisational strategy / innovation play in facilitating emerging skills?

4.What role does organisational culture / innovation play in facilitating emerging skills?

5.How will the cultural diversity of the workforce facilitate emerging skills? 


\section{Preliminary Innovative Skill Formation Framework}

This diagram acknowledges the complexity of the skill transfer, absorption and creation processes within an intangible resource base and notes the possibility that organisations in this process utilise multiple policy and discourse routines.

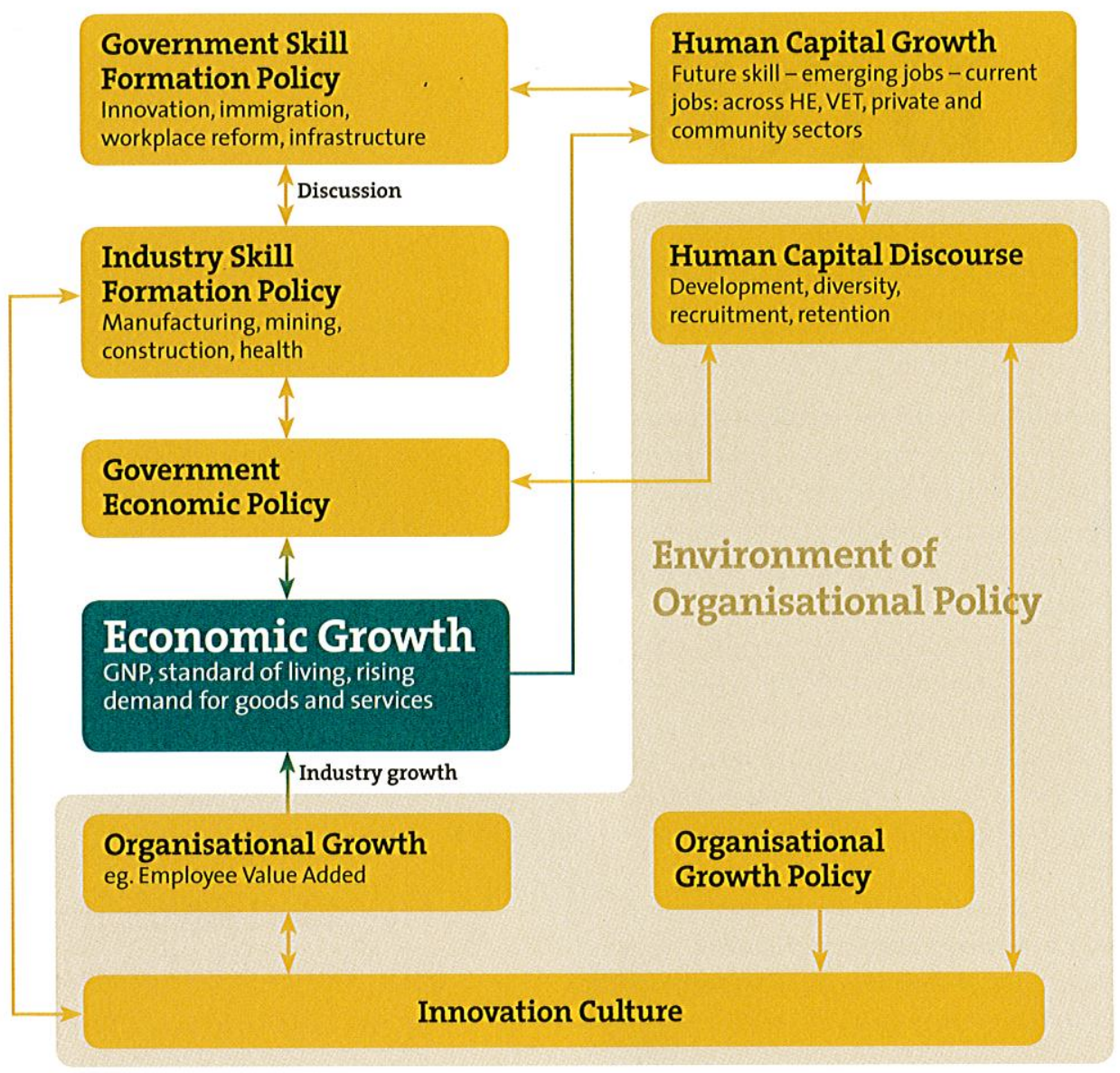

6. How has industry responded to the skills shortages, and emerging skills?

This study provides an opportunity to inform multi-level skill formation policy agendas in an effort to sustain Australia's economic growth. Thus, the development of an innovative national emerging skills framework provides:

-Benefits for the education sector in meeting the graduate attribute needs for the technical professions;

-Recommendations for organisational skill formation policy informed by research grounded in a theoretical framework and sensitive to the discursive power of key terms; -Recommendations for government and industry formation policy.

Finally, this study addresses frontier technologies for building and transforming Australian industries and businesses' ability to make more effective use of business models, systems and processes and the promotion of an innovation culture and economy through maximising Australia's creative and technological capability.

Professor Adela McMurray is the Assistant Dean, Research and Innovation, RMIT Business.

Dr Peter O'Neill is a Senior Lecturer in the Department of Management, Faculty of Business and Economics.

Professor John Buckeridge is Head of the Civil, Environmental and Chemical Engineering School at RMIT. Julie Wolfram-Cox is a Professor of Management, School of Management and Marketing, Deakin University.

To view this paper in full,

see www.mbr.monash.edu.au. 